\title{
Quantitative Study of Verbal Communication of the Teacher toward Girls and Boys
}

\author{
Mouna Kcharem Dammak ${ }^{1,2}$, Fairouz Azaiez',2, Mourad Bahloul ${ }^{3}$ \\ ${ }^{1}$ High Institute of Sport and Physical Education of Sfax, Sfax, Tunisia \\ ${ }^{2}$ Studies Group of Development and Social Environment (Faculty of Letters and Social Sciences of Sfax), Sfax, \\ Tunisia \\ ${ }^{3}$ Business School of Sfax, Sfax, Tunisia \\ Email: fairouz.kyranis@yahoo.com
}

Received 11 May 2015; accepted 10 July 2015; published 13 July 2015

Copyright (C) 2015 by authors and Scientific Research Publishing Inc.

This work is licensed under the Creative Commons Attribution International License (CC BY).

http://creativecommons.org/licenses/by/4.0/

(c) (i) Open Access

\begin{abstract}
This study aims to observe the activity of teachers with girls and boys with respect to an object of teaching: the Handstand in gymnastics in college. Many studies have allowed us to see that the school participates in the construction of an "educational inequality" between girls and boys (Vigneron, 2006; Cogérino, 2007). Our study population is composed of 8 teachers of EPS (4 men and 4 women) and 176 eighth-grade students. The analysis of the content of communications (organization, incentives, discipline and teaching content) shows us that there is a significant difference between the gender of teachers and the nature of the communications. So the role of context appears to act at both poles of the didactic interaction (teacher profile and solicitations of students). These two factors combine to determine the interactions of the teacher in learning situations.
\end{abstract}

\section{Keywords}

Verbal Communication, Teachers, Physical Education, Gender

\section{Introduction}

Today, verbal communication (refers to speech, language) seems to be an essential link and source of action in relations among individuals. The use of verbal communication is $80 \%$ when interacting with others that appear to be an excellent way when searching efficiency (Falzon, 1989; Benaiges, 2000). Marsenach and Merand (1987) selected four categories that define this speech and are relative communications on teaching content and that is related to whatever is linked both to the operation of the task and also to the action motive of the student. The organizational and verbal communications refer to temporal and spatial aspects hardware of the session and the 
conduct of the course. Verbal communications are incentive, and include all oral indications before and during the action encourage and congratulate the students after the action. Finally disciplinary verbal communications correspond to slight or severe reprimands by the teacher.

Despite this, Miyata (2004) and Loisier (2009) perceive the need to review the teacher's speech to the students to realize that there are many parameters to take into account (speed, intonation, punctuation and timely) when we try to have an effect on verbal communication. Thus, oral communication plays an important role in a balanced and harmonized academic program because it helps to develop skills in all subjects of the curriculum (Hill \& Kathleen, 2006; Miyata, 2004). Indeed, more than ever, we speak, we verbalise in our teaching, and dialogue is recommended in the discourse of teachers (Lebrun, 2007; Loisier, 2009). This relationship to knowledge as noted by Vinson (2013) is not without link with gender, level and identity processes in terms of girl and boy. The school, as other institutions, reproduces what happens in society in terms of gender relations. Indeed, the school participates in the construction of a "school inequality" between girls and boys (Vigneron, 2006; Cogérino 2007; Cogérino \& Trottin, 2009; Dubet et al., 2010; Merle, 2000, 2009). The Sports and Physical Activities are historically and symbolically from the masculine. In many cultures (ancient or modern), it is considered one of the fundamental elements of the construction of masculinity (Terret, 2004; Couchot-Schiex, 2000; Ritter, 2004). Therefore, the physical practices are sexually marked, and different gender stereotypes are at work (Baudelot \& Establet, 2007; Mosconi, 2004; Marro, 2012). Teachers' expectations, the weight of stereotypes, Physical Activity, Sport and Artistic sexually marked are factors that involve some inequality in terms of gender (Vinson, 2013). Indeed, Mosconi $(1998,2001)$ found that 56\% of teachers' interventions addressed to boys against 44\% to girls. However, McBride (1990) found that the Sports and Physical Education teachers (elementary, middle and high school) interact fairly with girls and boys. For Davisse (2004) and Weiller \& Doyle (2001) it is the girls who interact more with teachers and vice versa for boys. Teachers talk differently to girls and boys (Wright, 1999, 2000). Mosconi and Loudet-Verdier (1997) noted that teachers (male or female) develop more verbal interactions with boys than girls. They also note that the content of mathematics interactions is also differentiated between girls and boys; in general teachers address more questions to boys. By cons, as part of the Physical Education and Sports, Wright (1997) specified that the teacher builds longer dialogues with girls than with boys while exchanges are shorter. He added that boys receive more compliments from teachers than girls. They are encouraged on the success of the task that girls are supported for general actions. Furthermore, Physical Education is a discipline where the biological differences have such character evidence that they can hide the social dimension (Combaz, 1992). Contrary to what is observed when all disciplines are combined in Physical Education, girls are less successful than boys. If one refers to the results of the Sports and Physical Education events for which the nature of the proposed teaching situations contributes to embarrass many of the girls (Davisse \& Volondat, 1987; Moreno, 2006). Couchot-Schiex and Trottin (2005) have confirmed that the number of motor interactions at the Sports and Physical Education sessions is in favor of boys. If girls and boys receive much feedback to the transmission of information, the boys receive more orders approving the appointment of them to structure the learning situation and organize their work. Mosconi (1989), Duru-Bellat (1995) and Felouzis (1997) also show that the teachers are addressed differently to boys and girls, it is unconsciously, and that objectives interactions are also different. The feedback is also distributed differently to students by gender (Dunbar \& O'Sullivan, 1986; MacDonald, 1990, 2001). Indeed, the results also showed that the number of disciplinary verbal communication towards boys is significantly higher than that at the girls. Thus, the authority belongs rather the preserve "natural" to boys, is facilitated in Sport and Physical Education through physical allure. Girls are sometimes forced to fight against their female image (Bouchard et al., 2001). In addition, girls are not receiving more communications related to the organization contrary to the results of the research of MacDonald (1990). Finally, although the literature is that interactions are less stimulating for girls (Duru-Bellat 1995). However, boys are significantly more disciplinary communications simple and conditional directive type girls. As against, girls receive more value judgment type of incentive communications (Cogérino \& Lechelard, 2003). In this sense, Simpson and Erickson (1983) and De Voe (1991) state that if teachers interact more with boys, this is not to discriminate against girls, but rather because of the behaviors and attitudes of boys, as they are more active and more seek the teacher. That is why the most recent research seems, moreover, to be oriented more towards the consideration of the context and dynamics of the class (Parker, 1996; Wilkinson \& Fungi, 2002, Skelton, 2002).

This research had the purpose to characterize the activity of PE teachers in order to identify the differential treatment of girls and boys in the educational interaction between teachers/students. It was particularly interested in verbal communication for teachers against girls and boys and the role of context that may act on this didactic interaction. 


\section{Method}

This study aims to observe the activity of teachers with girls and boys with respect to an object of teaching: the Handstand in gymnastics in college. Our study population is composed of 8 teachers (4 men and 4 women) of Physical Education and Sport and 176 eighth grade students (86 boys and 90 girls) from the College August 13, 1956 in the center of the city of Sfax (Tunisia). This was a population with an average socio-economic background. The teachers are all volunteers, aged from 25 to 50 years, and have professional experience ranging from 3 to 28 years. Data are collected on video and audio recording of all actions and teacher interventions and students. The device uses the coupling sound/image in order to bring together, the behave or of different actors and the words of each (instructions, private or public remarks, verbal reactions of the teacher and students).The teacher was equipped with a lapel microphone to record the content of verbal communication that he/she had with her students from their grip until the end of the session. For classification, we relied on the work of Bardin (2013) to cut our communications into semantic units, larger units of meaning that the phrase ("categorization box”). By cons, for those categories for the organization, discipline, incitement and educational content, we relied on the work of Marsenach \& Merand (1987).

\section{Results and Discussion}

Data analysis (Table 1) shows the existence of a statistical association between-verbal communication of teachers and learners (girls and boys) $\left(\mathrm{X}^{2}=8.18 \mathrm{df}=2\right.$ to $\left.p<0.05\right)$. Indeed, there is a significant difference between women and men teachers in their treatment of girls and boys. They develop more verbal interactions with boys (44.1\% vs 43\%) than girls (31.6\% vs 28.4\%).These results were confirmed by Mosconi studies (1999, 1998, 2001), Wright (1999, 2000) and McDonald (1990, 2001), Vinson (2013) and Cogérino \& Lechelard (2003). The Sports and Physical Education teachers are carriers of this sexist culture. For them, masculinity is often synonymous with strength, insurance and fight when femininity refers to notions of sweetness and grace. These different perceptions of girls and boys generate differentiated skills that affect student learning (Pygmalion effect).

Regarding the analysis of the content of communications (organization, incentives, discipline and teaching content). The results (Table 2) indicate that there is a significant relationship between students' gender and the nature of communications $\left(\mathrm{X}^{2}=46,039\right.$, $\left.\mathrm{df}=3 p<0.001\right)$.Thus, teachers are using more incentive verbal communication towards girls than boys (50.8\% vs $48.2 \%)$. By cons, Organizational verbal communications and communications-oriented to educational content are mostly to the joint unit (undifferentiated). But the types of disciplinary communications are much more frequently for boys. However, girls receive more incentives communications and communications on educational content. These results are validated by the work of Bouchard et al. (2001) and Duru-Bellat (1995) which state that boys are moving towards an image of "manhood” through loud and aggressive behaviors while girls emphasize that of a passive femininity.

However, the distribution of the nature of communications by gender of teacher, shows us that there is a significant difference between the gender of teachers and the nature of communications sent $\left(\mathrm{X}^{2}=14.91\right.$, $\mathrm{df}=3$ at $p<0.01$ ) (see Table 3). Indeed, our results suggest that women in their verbal communications, seem rather an

Table 1. The distribution of verbal communications by gender of teachers and students.

\begin{tabular}{cccc}
\hline & Girls & Boys & Undifferentiated \\
\hline Women teachers & $550(31.6 \%)$ & $767(44.1 \%)$ & $423(24.3 \%)$ \\
Men teachers & $398(28.4 \%)$ & $602(43 \%)$ & $400(28.6 \%)$ \\
\hline
\end{tabular}

Table 2. The distribution of categories of communications for girls and boys.

\begin{tabular}{|c|c|c|c|c|c|}
\hline \multicolumn{6}{|c|}{ Types of communications } \\
\hline & Organization & Discipline & Incitement & Content of Education. & Total \\
\hline Girls & $256(23.5 \%)$ & 34 (3.1\%) & $553(50.8 \%)$ & 245 (22.5\%) & $1088(100 \%)$ \\
\hline Boys & $389(24.8 \%)$ & 147 (9.4\%) & 755 (48.2\%) & $276(17.6 \%)$ & 1567 (100\%) \\
\hline Total & 645 (24.3\%) & 181 (6.8\%) & 1308 (49.3\%) & $521(19.6 \%)$ & 2655 (100\%) \\
\hline
\end{tabular}


Table 3. The distribution of types of communications by gender of teachers and students.

\begin{tabular}{cccccc}
\hline & & \multicolumn{3}{c}{ Types of Communications } \\
\cline { 2 - 6 } & Organization & Discipline & Incitement & $\begin{array}{c}\text { Content of } \\
\text { Education }\end{array}$ & Total \\
\hline Women Teachers & $327(21.6 \%)$ & $102(6.7 \%)$ & $782(51.7 \%)$ & $303(20 \%)$ & $1514(100 \%)$ \\
Men Teachers & $318(27.9 \%)$ & $79(6.9 \%)$ & $526(46.1 \%)$ & $218(19.1 \%)$ & $1141(100 \%)$ \\
Total & $645(24.3 \%)$ & $181(6.9 \%)$ & $1308(49.2 \%)$ & $521(19.6 \%)$ & $2655(100 \%)$ \\
\hline
\end{tabular}

incentive slope, while men on the other hand seem more concerned with what is organizational in nature as confirmed by Flintoff studies (1990, 1993), MacDonald (1990) and Wright (1997, 1999, 2000) who have shown that the Sports and Physical Education teachers unconsciously differences in objectives, treatment and interactions according to the gender of the students.

\section{Conclusion}

This research had the purpose to characterize the activity of eight of Sports and Physical Education teachers in order to identify the differential treatment of boys and girls in educational interactions between teachers/students. Thus, in her teaching, diversity alone is not a sufficient condition; it seems to eliminate inequalities and treatment practices and achieve equity between girls and boys in essential gymnastic. It shows us something about how teachers often "failed" their teachings. So the role of context appears to act at both poles of the didactic interaction (teacher profile and solicitations of students). These two factors combine to determine the interactions of the teacher in learning situations.

We found ourselves forced to limit our investigation on the differential treatment of girls and boys EPS by gender of teachers, for reasons related to the time constraints and the density of research. We hope he will continue with other work combining verbal and non-verbal interactions in the context of learning gymnastics but also in other physical and artistic disciplines.

\section{References}

Bardin, L. (2013). The Content Analysis, Collection Quadrige. Paris: PUF.

Baudelot, C. \& Establet, R. (2007). What's New in Girls? Between Stereotypes and Freedoms. Paris: Nathan.

Benaiges, O. (2000). Verbal Communication and Integration of the Teacher to the Class of 6th, Memory Professional, IUFM of the Academy of Montpellier.

Bouchard, P., Saint-Amant, J. C., \& Gagnon, C. (2001). Sex Practices in Québec Schools. Canadian Journal of Education, 25, 73-87. http://dx.doi.org/10.2307/1585742

Cogérino, G., \& Lechelard, F. (2003). Social Categorization of Students and Gender Stereotypes in EP? Communication to Study Days of the French Society of Sport Psychology, Paris: Charléty.

Cogérino, G. (2007). About PE Teachers Facing the Mix. Staps1, No. 75, 25-42.

Cogérino, G., \& Trottin, B. (2009). Girls and Boys in EPS: Descriptive Approach of Verbal Interactions between Teachers and Students. STAPS Review, No. 83, 70-83.

Combaz, G. (1992). Sociology of Physical Education. Evaluation and Inequalities of Success. Paris: PUF.

Couchot-Schiex, S. (2000). Curricula and Sexual Identity in Physical and Sports Education.DEA in Sciences of Education. Lyon: University of Lyon II.

Couchot-Schiex, S., \& Trottin, B. (2005). Interactions Teachers/Pupils EPS: Variations by Gender and Gender. In G. Cogérino (Ed.), Girls and Boys in EPS (pp. 163-179). Paris: Editions of the Revue EPS.

Davisse, A., \& Volondat, M. (1987). Mix, Pedagogy and Educational Differences. EPS Review, No. 206, 53-56.

Davisse, A. (2004). The Mix in Question: Review against Foot \# 15. EPS and Society Centre, SNEP, 28-31.

De Voe, D. E. (1991). Teacher Behavior Directed toward Individual Students in Elementary Physical Education. Journal of Classroom Interaction, 26, 9-14.

Dubet, D., Duru-Bellat, M., \& Vérétout, A. (2010). Companies and Their School. Grasp diplômeet Social Cohesion, Seuil, Paris. 
Dunbar, R. R., \& O’Sullivan, M. M. (1986). Effects of Intervention on Differential Treatment of Boys and Girls in Elementary Physical Education Lessons. Journal of Teaching in Physical Education, 5, 166-175.

Duru-Bellat, M. (1995). Girls and Boys in School, Sociological and Psychosocial Approaches: School Construction Differences. French Review of Education, 110, 75-110.

Falzon, P. (1989). Cognitive Ergonomics of the Dialogue. Grenoble: Presses Universitaires de Grenoble.

Felouzis, G. (1997). The Effectiveness of Teachers. Paris: PUF.

Hill, J. D., \& Kathleen, M. F. (2006). Classroom Instruction That Works with English Language Learners. Alexandria (Virginie), États-Unis: Association for Supervision and Curriculum Development.

Lebrun, M. (2007). Technologies for Teaching and Learning. Brussels: De Boeck.

Loisier, J. (2009). Educational Communication Guide and Technology Choices in Distance Education. Paper Prepared for the Francophone Education Network Remote Canada (REFAD), Department of Canadian Heritage.

MacDonald, D. (1990). The Relationship between the Sex Composition of Physical Education Classes and Teacher-Pupil Verbal Interaction. Journal of Teaching in Physical Education, 9, 152-163.

MacDonald, D. (2001). Extending Agendas: Physical Culture Research for the 21th Century. In D. Penney (Ed.), Gender and Physical Education: Contemporary Issues and Future Directions. London and New York: Routledge.

Marro, C. (2012). Dependence/Independence from the Genre: A Relevant Dimension for Thinking Gender Equality beyond Differences. Le Mirail: University of Toulouse.

Marsenach, J., \& Merand, R. (1987). Formative Assessment in Colleges. Coll. Research Report NPRI \# 2, Paris: NPRI.

McBride, R. E. (1990). Sex-Role Stereotyping Behaviors among Elementary, Junior, and Senior High School Physical Education Specialist. Journal of Teaching in Physical Education, 9, 249-261.

Merle, P. (2000). The Concept of Democratization of the School Institution: A Typology and Its Testing Period. Population, $55,15-50$.

Merle, P. (2009). The Democratization of Teaching. Paris: La Découverte.

Miyata, C. (2004). The Art of Oral Communication. Montreal: The McGraw-Hill Ryerson.

Moreno, C. (2006). Mixed Forms and EPS Inequalities in Achievement between Girls and Boys. In G. Cogérino (Ed.), The Diversity in Physical Education and Sports. Lyrics, Successes, Differentiations (pp. 40-54). Paris: Editions of the Revue EPS.

Mosconi, N. (1989). The Diversity in Secondary Education: A False Pretense? Paris: PUF.

Mosconi, N. (2001). How Do They Make the Teaching Practices of Gender Inequality? Records of Sciences of Education, 5 , 97-109.

Mosconi, N. (2004). Effects and Limits of Co-Education. Work, Gender and Societies, 11, 165-174.

Mosconi, N., \& Loudet-Verdier, J. (1997). Unequal Treatment of Girls and Boys. In C. Blanchard-Laville (Ed.), Variations on a Math Lesson (pp. 127-150). Paris: l'Harmattan.

Parker, A. (1996). The Construction of Masculinity within Boy’s Physical Education. Gender and Education, 8, $141-157$. http://dx.doi.org/10.1080/09540259650038824

Ritter, D. (2004). Gender Role Orientation and Performance on Stereotypically Feminine and Masculine Cognitive Tasks. Sex Roles, 50, 583-591. http://dx.doi.org/10.1023/B:SERS.0000023077.91248.f7

Simpson, A. W., \& Erickson, M. T. (1983). Teachers' Verbal and Nonverbal Communication Patterns as a Function of Teacher Race, Student Gender, and Student Race. American Educational Research Journal, 20, 183-198. http://dx.doi.org/10.3102/00028312020002183

Skelton, C. (2002). Constructing Dominant Masculinity and Negotiating the Male Gaze. International Journal of Inclusive Education, 6, 17-31. http://dx.doi.org/10.1080/136031102753389819

Terret, T. (2004). Sport and Masculinity: A Review of Questions. STAPS Journal, 66, 209. http://dx.doi.org/10.3917/sta.066.0209

Vigneron, C. (2006). Inequality of Success in EPS between Boys and Girls: Biological Determinism or School French Manufacturing. Review of Education, 154, 11-124.

Vinson, M. (2013). Under the Dynamic Teaching Nonverbal Interactions, Gender: Analysis of the Joint Action of the Teacher and Students: EPS Two Case Studies. Ph.D. Thesis, Le Mirail: University of Toulouse 2.

Weiller, K. H., \& Doyle, E. J. (2000). Teacher-Student Interaction: An Exploration of Gender Differences in Elementary Physical Education. Journal of Physical Education, Recreation and Dance, 71, 43-45.

http://dx.doi.org/10.1080/07303084.2000.10605112 
Wilkinson, I. A. G., \& Fungi, I. Y. (2002). Small-Group Composition and Peer Effects. International Journal of Educational Research, 37, 425-447. http://dx.doi.org/10.1016/S0883-0355(03)00014-4

Wright, J. (1997). The Construction of Gendered Contexts in Single Sex and Co-Educational Physical Education Lessons. Sport, Education and Society, 2, 55-72. http://dx.doi.org/10.1080/1357332970020104

Wright, J. (1999). Changing Gendered Practices in Physical Education: Working with Teachers. European Physical Education Review, 5, 181-197. http://dx.doi.org/10.1177/1356336X990053002

Wright, J. (2000). Revisiting Gender Equity in Physical Education. Proceedings of the AERA Annual Meeting, New Orleans, 24-28 April 2000, 24-28. 